\title{
Simultaneous induction of mutant alleles of two allergenic genes in soybean by using site-directed mutagenesis
}

Shota Sugano ${ }^{1}$, Aya Hirose ${ }^{1}$, Yuhei Kanazashi ${ }^{1}$, Kohei Adachi $^{1}$, Miki Hibara ${ }^{1}$, Takeshi Itoh ${ }^{2} \mathbb{D}$, Masafumi Mikami ${ }^{3}$, Masaki Endo ${ }^{3}$, Sakiko Hirose ${ }^{3}$, Nobuyuki Maruyama ${ }^{4}$, Jun Abe $^{1}$ and Tetsuya Yamada ${ }^{1 *}$ (D)

\begin{abstract}
Background: Soybean (Glycine max) is a major protein crop, because soybean protein has an amino acid score comparable to that of beef and egg white. However, many allergens have been identified among soybean proteins. A decrease in allergenic protein levels would be useful for expanding the market for soybean proteins and processed foods. Recently, the CRISPR/Cas9 system has been adopted as a powerful tool for the site-directed mutagenesis in higher plants. This system is expected to generate hypoallergenic soybean varieties.

Results: We used two guide RNAs (gRNAs) and Agrobacterium-mediated transformation for simultaneous sitedirected mutagenesis of two genes encoding the major allergens Gly $\mathrm{m} \mathrm{Bd} 28 \mathrm{~K}$ and $\mathrm{Gly} \mathrm{m} \mathrm{Bd} 30 \mathrm{~K}$ in two Japanese soybean varieties, Enrei and Kariyutaka. We obtained two independent $T_{0}$ Enrei plants and nine $T_{0}$ Kariyutaka plants. Cleaved amplified polymorphic sequence (CAPS) analysis revealed that mutations were induced in both targeted loci of both soybean varieties. Sequencing analysis showed that deletions were the predominant mutation type in the targeted loci. The Cas9-free plants carrying the mutant alleles of the targeted loci with the transgenes excluded by genetic segregation were obtained in the $T_{2}$ and $T_{3}$ generations. Variable mutational spectra were observed in the targeted loci even in $T_{2}$ and $T_{3}$ progenies of the same $T_{0}$ plant. Induction of multiple mutant alleles resulted in six haplotypes in the Cas9-free mutants derived from one $\mathrm{T}_{0}$ plant. Immunoblot analysis revealed that no Gly m Bd $28 \mathrm{~K}$ or Gly m Bd $30 \mathrm{~K}$ protein accumulated in the seeds of the Cas9-free plants. Wholegenome sequencing confirmed that a Cas9-free mutant had also no the other foreign DNA from the binary vector. Our results demonstrate the applicability of the CRISPR/Cas9 system for the production of hypoallergenic soybean plants.
\end{abstract}

Conclusions: Simultaneous site-directed mutagenesis by the CRISPR/Cas9 system removed two major allergenic proteins from mature soybean seeds. This system enables rapid and efficient modification of seed components in soybean varieties.

Keywords: CRISPR/Cas9, Glycine max, Gly m Bd 28 K, Gly m Bd 30 K, Hypoallergenic soybean

\footnotetext{
*Correspondence: tetsuyay@res.agr.hokudai.ac.jp

'Graduate School of Agriculture, Hokkaido University, Kita 9, Nishi 9, Kita-ku, Sapporo, Hokkaido 060-8589, Japan

Full list of author information is available at the end of the article
}

(c) The Author(s). 2020 Open Access This article is licensed under a Creative Commons Attribution 4.0 International License, which permits use, sharing, adaptation, distribution and reproduction in any medium or format, as long as you give appropriate credit to the original author(s) and the source, provide a link to the Creative Commons licence, and indicate if changes were made. The images or other third party material in this article are included in the article's Creative Commons licence, unless indicated otherwise in a credit line to the material. If material is not included in the article's Creative Commons licence and your intended use is not permitted by statutory regulation or exceeds the permitted use, you will need to obtain permission directly from the copyright holder. To view a copy of this licence, visit http://creativecommons.org/licenses/by/4.0/ The Creative Commons Public Domain Dedication waiver (http://creativecommons.org/publicdomain/zero/1.0/) applies to the data made available in this article, unless otherwise stated in a credit line to the data. 


\section{Background}

Soybean (Glycine $\max , 2 n=2 x=40$ ) is one of the most important protein crops used for food and forage worldwide, because its seeds contain high-quality proteins with an amino acid score comparable to that of beef and egg white [1]. Diverse soybean proteins are responsible for the physical properties of foods and other products made from soybean seeds $[2,3]$. In the USA and Europe, 5 to $8 \%$ of babies and $2 \%$ of adults are allergic to soybean [4]. Several subunits of major storage proteins such as $7 \mathrm{~S}$ and $11 \mathrm{~S}$ globulins and $2 \mathrm{~S}$ albumin are representative soybean allergens [5]. The vicilin-like glycoprotein Gly $\mathrm{m} \mathrm{Bd} 28 \mathrm{~K}$ and the oilbody-associated protein Gly $\mathrm{m} \mathrm{Bd} 30 \mathrm{~K}$ are also reported as major soybean allergens [6, 7]. Hydrophobic proteins Gly $\mathrm{m} 1 \mathrm{~A}$ and Gly $\mathrm{m} \mathrm{1B}$ and the hull protein Gly $\mathrm{m} 2$ are related to asthma outbreaks in Spain [8, 9]. Profilin Gly m 3 and the pathogenesis-related protein Gly $\mathrm{m} 4$ are crossreactive with antigens from other sources involved in sensitization and symptom induction $[10,11]$. Positive response to soybean protein in allergic reaction has been reported in $14 \%$ of patients diagnosed with food allergies with atopic dermatitis [12]. Therefore, development of hypoallergenic soybean varieties or establishment of a procedure to remove allergens would be useful for expanding the market of soybean proteins and processed foods.

Protein fractionation on the basis of the differences in protein solubility at different salt concentrations and $\mathrm{pH}$ can be used to characterize the biochemical and physical properties of proteins [13-15]. This technique is also used for the removal of specific allergens from soy foods. Gly m Bd $30 \mathrm{~K}$ was efficiently removed from soy milk by acidifying it to $\mathrm{pH} 4.5$ with $1 \mathrm{M} \mathrm{Na}_{2} \mathrm{SO}_{4}$ [16].

Genetic improvement of soybean is achieved by crossing plants carrying allergen-deficient alleles from soybean genetic resources or by mutagenesis to generate allergen-deficient mutant alleles. A number of spontaneous or induced mutants deficient in subunits of $7 \mathrm{~S}$ or $11 \mathrm{~S}$ globulins have been reported [17-20]. Among the germplasm of wild soybean (G. soja), Hajika et al. [20] found one accession lacking the $\alpha_{-}, \alpha^{\prime}-$, and $\beta$-subunits of 7S globulin. The deficiency of these subunits is controlled by a single dominant gene $(S c g-1)$, which is closely associated with post-transcriptional gene silencing [21]. To develop hypoallergenic soybean through crossing and subsequent back-crossing, this dominant gene has been introduced into an elite variety, Fukuyutaka [22]. The soybean variety Yumeminori lacks $\alpha$ - and $\alpha$-subunits of $7 \mathrm{~S}$ globulin, and Gly $\mathrm{m} \mathrm{Bd} 28 \mathrm{~K}$, and has a decreased level of the $\beta$-subunit of 7S globulin; this variety has been developed through mutagenesis by gamma-ray irradiation [23]. Mutagenesis of the soybean variety VLSoy-2 by gamma-ray irradiation generated mutant lines lacking the A3-subunit of $11 \mathrm{~S}$ globulin [24]. This mutagenesis also produced plants lacking $\alpha-$ and $\alpha$ '-subunits of 7S globulin [24]. Stacking of recessive mutant alleles of the genes for Kunitz trypsin inhibitor, agglutinin, and Gly $\mathrm{m}$ Bd $30 \mathrm{~K}$ was performed in the genetic background of the soybean variety Williams 82 [25]. Proteome analysis revealed that the stacking of these mutant alleles markedly decreased the accumulation of these allergens [25].

The biotechnological approach can also help to decrease the accumulation of allergens in soybean seeds. Down-regulation of the gene encoding Gly m Bd $30 \mathrm{~K}$ greatly suppresses the accumulation of the targeted protein in seeds of transgenic soybean [26]. The accumulation of $\alpha-, \alpha^{\prime}-$, and $\beta$-subunits of $7 \mathrm{~S}$ globulin in soybean seeds can be greatly decreased through RNA interference or artificial microRNA systems [27, 28]. Recently, the transcription activator-like effector nucleases (TALE Ns) and clustered regularly interspaced short palindromic repeats (CRISPR)/CRISPR-associated endonuclease 9 (Cas9) systems have become the main platforms for site-directed mutagenesis in higher plants [29-32]. They enable the fine tuning of traits in soybean breeding when applied to various soybean varieties. The CRISPR/ Cas9 system can be used to develop hypoallergenic soybean directly from elite varieties, because it has been optimized for various soybean varieties [33-37].

The subunits of 7S and 11S globulins are closely associated with seed characteristics important for food processing such as gel-forming and emulsifying properties [38-40]. To produce hypoallergenic soybeans without impairing the processing properties, we focused on two allergenic proteins, Gly m Bd $28 \mathrm{~K}$ and Gly m Bd $30 \mathrm{~K}$, because no pyramiding of mutant alleles of these allergens in soybean has been reported. Here, we constructed a plasmid for simultaneous site-directed mutagenesis of these genes with the CRISPR/Cas9 system and used it for Agrobacterium-mediated transformation of two soybean varieties. Cas9-free plants carrying mutant alleles of the targeted loci, with the transgenes excluded by genetic segregation, were obtained in the $T_{2}$ or $T_{3}$ generations. Immunoblot analysis revealed that Gly $\mathrm{m} \mathrm{Bd}$ $28 \mathrm{~K}$ and Gly $\mathrm{m} \mathrm{Bd} 30 \mathrm{~K}$ proteins did not accumulate in seeds of the Cas9-free plants. Our results demonstrate the applicability of the CRISPR/Cas9 system for the production of hypoallergenic soybean plants.

\section{Results}

Generation of transgenic soybean plants harboring the CRISPR/Cas9 expression module.

To conduct the site-directed mutagenesis of soybean with the CRISPR/Cas9 system, we designed two guide RNAs (gRNAs) to mutagenize the Gly $m B d 28 K$ and Gly $m$ Bd $30 \mathrm{~K}$ loci (Fig. 1a). Explants of Enrei and Kariyutaka were inoculated with Agrobacterium harboring the pMR284_28K_30K plasmid (Fig. 1b). Two Enrei $\mathrm{T}_{0}$ 


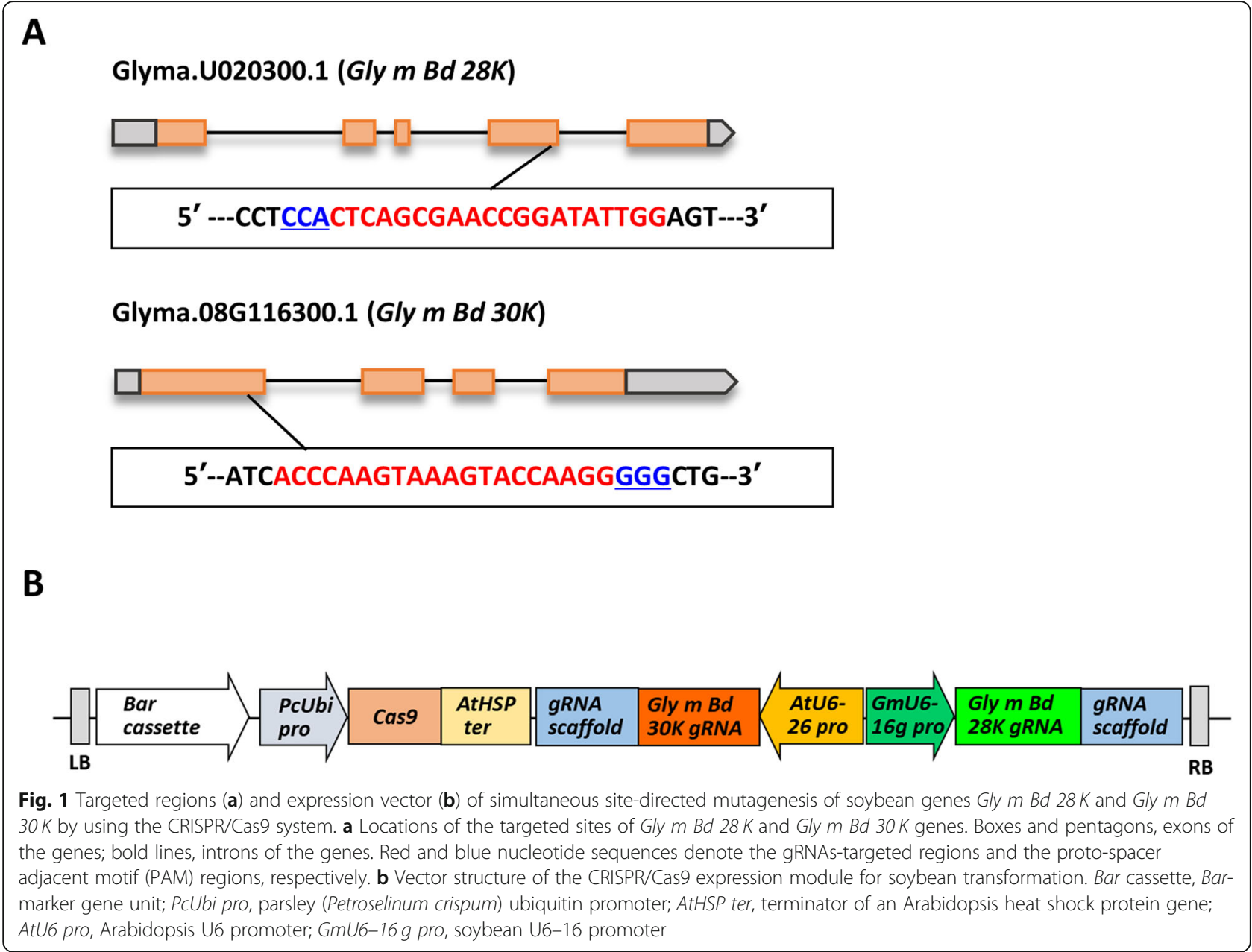

plants (E1 and E2) and nine Kariyutaka $\mathrm{T}_{0}$ plants (K1 to K10) were obtained. All the $T_{0}$ plants set $T_{1}$ seeds. In our previous study, many $\mathrm{T}_{0}$ plants produced by our soybean transformation system failed to transmit the transgenes into the $T_{1}$ progeny [41]. This fact indicates that $\mathrm{T}_{0}$ plants originated from chimeric tissues which contained transformed and non-transformed cells [41]. Therefore, we did not examine transgene integration or the induction of mutagenesis in the $\mathrm{T}_{0}$ plants, and grew representative $T_{1}$ plants for further analyses. The plant numbers of the $T_{1}$ and $T_{2}$ generations were indicated by giving the $\mathrm{T}_{0}$ individual number followed by the branch number for each generation.

\section{Mutations in $\mathrm{T}_{1}$ plants detected by cleaved amplified polymorphic sequence (CAPS) analysis}

Representative $20 \mathrm{~T}_{1}$ Enrei plants and $25 \mathrm{~T}_{1}$ Kariyutaka plants derived from $12 \mathrm{~T}_{0}$ plants were grown, and the induction of mutagenesis in the targeted loci was evaluated by CAPS analysis of the genomic DNA. The DNA fragments were classed into wild-type and mutant-type based on the expected size; a fragment of unexpected size was also detected and considered as mutant-type (Fig. 2). Mutations were detected in both targeted loci in plants of both varieties (Fig. 2, Additional file 2: Figure S1, Additional file 1: Tables S1, S2). Integration of the transgene was also examined by PCR analysis with Cas9specific primers. PCR analysis revealed that $11 \mathrm{~T}_{1}$ plants (24.4\% of all $\mathrm{T}_{1}$ plants examined) were Cas9-free; among these, E1-4, E1-8, and E1-9 had mutant alleles in the Gly $m \mathrm{Bd} 30 \mathrm{~K}$ locus, whereas the others had the wildtype alleles of both targeted loci (Additional file 1: Tables S1, S2).

\section{Transmission of mutations and transgenes to the $T_{2}$ generation}

Because none of the Cas9-free $\mathrm{T}_{1}$ plants had mutations in both targeted loci, 13 representative $T_{1}$ plants were advanced to the next generation. A total of $348 \mathrm{~T}_{2}$ seeds collected from the $13 \mathrm{~T}_{1}$ plants were evaluated for the mutations in the targeted loci (Table 1). In CAPS analysis, 227 (65\%) $\mathrm{T}_{2}$ seeds showed mutant-type fragments of both targeted loci (Table 1, Additional file 2: Figs. S2, S3). No mutations were detected in $20 \mathrm{~T}_{2}$ seeds 


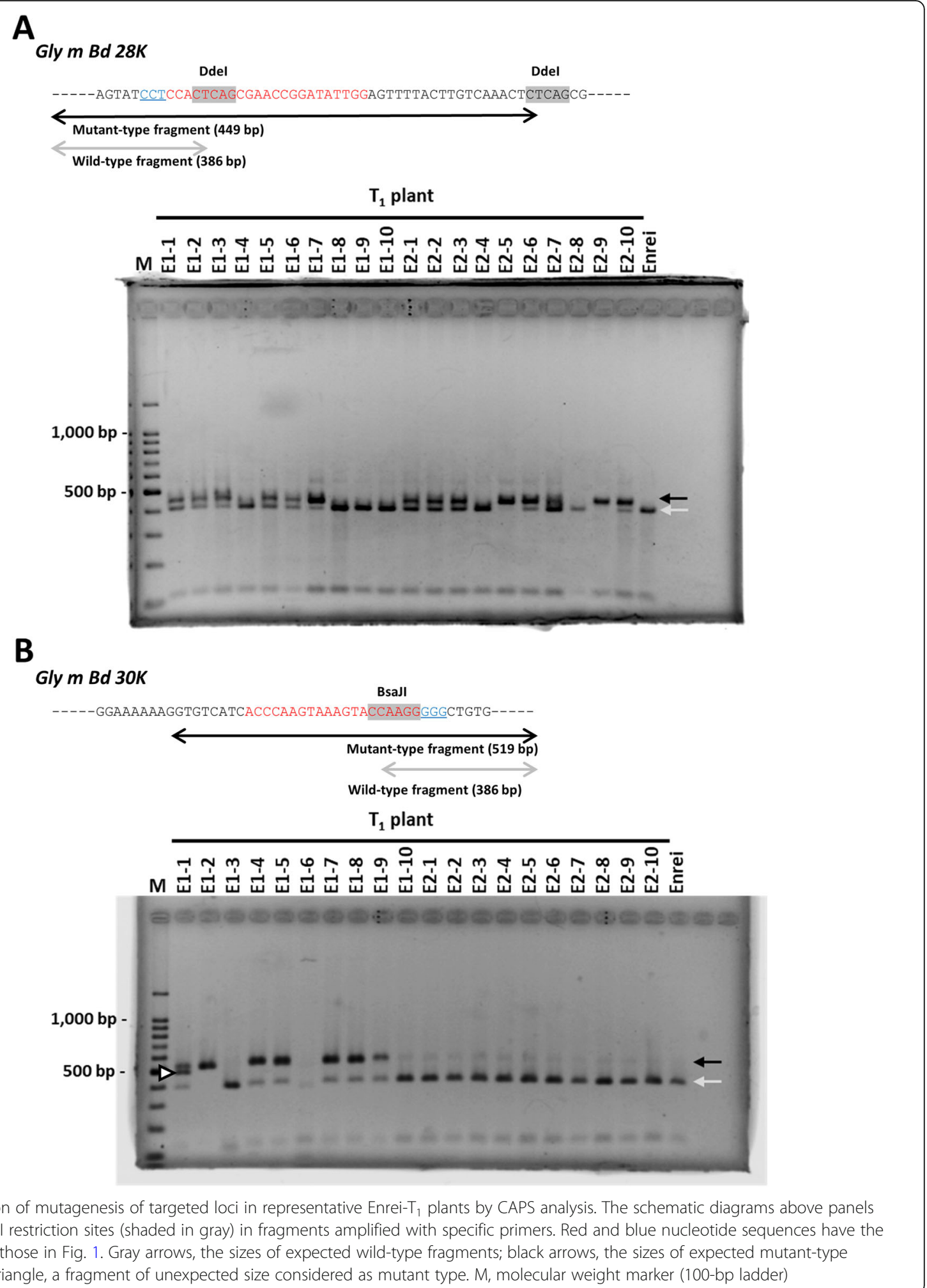

Fig. 2 Confirmation of mutagenesis of targeted loci in representative Enrei-T1 plants by CAPS analysis. The schematic diagrams above panels show Ddel or Bsall restriction sites (shaded in gray) in fragments amplified with specific primers. Red and blue nucleotide sequences have the same meaning as those in Fig. 1. Gray arrows, the sizes of expected wild-type fragments; black arrows, the sizes of expected mutant-type fragments; open triangle, a fragment of unexpected size considered as mutant type. M, molecular weight marker (100-bp ladder)

(Table 1). Thus, frequency of simultaneous site-directed mutagenesis in both targeted loci was much higher in the $\mathrm{T}_{2}$ generation than in the $\mathrm{T}_{1}$ generation (Table 1 , Additional file 1: Tables S1, S2).
Although the Cas 9 gene was detected in all $13 \mathrm{~T}_{1}$ plants (Additional file 1: Tables S1, S2), it was removed by genetic segregation in $52 \mathrm{~T}_{2}$ seeds (Table 2, Additional file 2: Fig. S4). Among them, $38 \mathrm{~T}_{2}$ seeds had 
Table 1 Frequency of simultaneous site-directed mutagenesis in the targeted loci Gly $m$ Bd $28 \mathrm{~K}$ and Gly $\mathrm{m} \mathrm{Bd} 30 \mathrm{~K}$ in $\mathrm{T}_{2}$ seeds

\begin{tabular}{|c|c|c|c|c|c|}
\hline \multirow{3}{*}{$\begin{array}{l}\mathrm{T}_{1} \text { plant } \\
\text { number }^{\mathrm{a}}\end{array}$} & \multicolumn{5}{|l|}{ Number of $T_{2}$ seeds } \\
\hline & \multicolumn{3}{|l|}{ Mutation } & \multirow{2}{*}{$\begin{array}{l}\text { No } \\
\text { mutation }\end{array}$} & \multirow[t]{2}{*}{ Total } \\
\hline & Gly $m$ Bd $28 \mathrm{~K}$ and Gly $\mathrm{m} \mathrm{Bd} 30 \mathrm{~K}$ & Gly $m$ Bd $28 K$ only & Gly $m$ Bd $30 K$ only & & \\
\hline E1-1 & 18 & 11 & 8 & 2 & 39 \\
\hline E1-2 & 22 & 0 & 3 & 0 & 25 \\
\hline E1-5 & 9 & 4 & 3 & 1 & 17 \\
\hline E2-1 & 0 & 22 & 0 & 10 & 32 \\
\hline E2-2 & 1 & 20 & 0 & 5 & 26 \\
\hline $\mathrm{K} 1-1$ & 12 & 1 & 0 & 0 & 13 \\
\hline $\mathrm{K} 1-3$ & 16 & 3 & 4 & 2 & 25 \\
\hline K2-1 & 17 & 3 & 3 & 0 & 23 \\
\hline K2-2 & 20 & 7 & 4 & 0 & 31 \\
\hline K4-1 & 35 & 0 & 2 & 0 & 37 \\
\hline K5-1 & 50 & 0 & 0 & 0 & 50 \\
\hline K5-2 & 14 & 1 & 0 & 0 & 15 \\
\hline K6-1 & 12 & 3 & 0 & 0 & 15 \\
\hline
\end{tabular}

The presence of mutations was evaluated by CAPS analysis

${ }^{a}$ The letter and first number correspond to the number of the parental $\mathrm{T}_{0}$ plant

mutant alleles in one or both targeted loci (Table 2). Of these 38 seeds, 14 seeds belonging to both varieties had mutant alleles in both targeted loci (double-mutants; Table 2). Representative mutational spectra of the $T_{2}$ seeds are shown in Fig. 3. The genotypes were divided into homozygous (the Gly $m$ Bd $28 \mathrm{~K}$ locus in K4-1-37 and Gly $m$ Bd $30 \mathrm{~K}$ locus in E1-5-17, K1-3-11, and K41-37 $\mathrm{T}_{2}$ seeds), heterozygous (the Gly $m$ Bd $28 \mathrm{~K}$ locus in E1-2-6 and E1-5-17, and $\mathrm{K} 1-3-11 \mathrm{~T}_{2}$ seeds), and biallelic mutant types (the Gly $\mathrm{m} \mathrm{Bd} 30 \mathrm{~K}$ locus in E1-26) (Fig. 3). Deletions were predominant in the mutational spectra of these $T_{2}$ seeds (Fig. 3).

\section{Development of double-mutant $T_{3}$ seeds}

We used the heterozygous and biallelic mutants to develop more homozygous mutant alleles. We collected $T_{3}$ seeds and sequenced both targeted loci. In total, 4 haplotypes in Enrei and 21 haplotypes in Kariyutaka were found in the double-mutants (Table 3). Deletions (1 to 43 nucleotides) were the most common mutations (Table 3, Additional file 2: Figure S5). Predicted amino acid sequences of Gly m Bd $28 \mathrm{~K}$ (Figure S6) and Gly m Bd $30 \mathrm{~K}$ (Figure S7) are shown in Additional file 2. Three mutant alleles ( $d 3$ and $d 6$ for the Gly $m B d 28 K$ locus, and $d 6$ for the Gly $m B d 30 \mathrm{~K}$ locus) had in-frame mutations (Additional file 2: Figures S6, S7). In the Gly m Bd $30 \mathrm{~K}$ locus, the 3-nucleotide deletion generated a stop codon at the mutation site, and the 33-nucleotide deletion was not predicted as an in-frame mutation, because the deleted region contained the splicing site (Additional file 2: Figure S7).

\section{Analysis of Gly m Bd $28 \mathrm{~K}$ and Gly $\mathrm{m} \mathrm{Bd} 30 \mathrm{~K}$ proteins in} mature double-mutant seeds

We selected two Enrei haplotypes (E-type1 and E-type3) and seven Kariyutaka haplotypes (K-type2, K-type4, Ktype7, K-type9, K-type14, K-type15, and K-type19) from the double-mutants (Table 3), and examined the composition of crude protein fractions prepared from mature seeds. The Gly $\mathrm{m} \mathrm{Bd} 30 \mathrm{~K}$ protein was visually detectable in Enrei and Kariyutaka but not mutant seeds, whereas Gly m Bd $28 \mathrm{~K}$ was not detectable in any seeds in the SDS-PAGE analysis (Fig. 4a). The double-mutant seeds had no signal bands that were not detected in wild-type seeds (Fig. 4a). To detect the Gly m Bd $28 \mathrm{~K}$ and Gly $\mathrm{m}$ Bd $30 \mathrm{~K}$ proteins specifically, immunoblot analysis was conducted in double-mutant and wild-type seeds. In the immunoblot analysis, the Gly m Bd $28 \mathrm{~K}$ and Gly $\mathrm{m} \mathrm{Bd} 30 \mathrm{~K}$ proteins were detected only in seeds of wild-type Enrei or Kariyutaka, except that Gly m Bd $28 \mathrm{~K}$ was also detected in the E-type 3 haplotype (Fig. $4 \mathrm{~b}$, c). No immunoreactive band of unexpected size was detected (Additional file 2: Figure S8).

\section{Expression levels of the Gly $m B d 28 K$ and the Gly $m B d$ $30 \mathrm{~K}$ genes}

To evaluate the expression levels of the Gly $m$ Bd $28 \mathrm{~K}$ and the Gly $m$ Bd $30 \mathrm{~K}$ genes, we extracted total RNA from the mature $\mathrm{T}_{3}$ seeds of two Enrei mutants (E-type1 and E-type3), seven Kariyutaka mutants (K-type2, Ktype4, K-type7, K-type9, K-type14, K-type15, and Ktype19), Enrei and Kariyutaka, and conducted semiquantitative RT-PCR analysis of the region up-stream of the mutation site (Additional file 2: Figure S9). Although 
Table 2 Frequency of Cas9-positive and Cas9-free $T_{2}$ seeds

\begin{tabular}{|c|c|c|c|c|c|c|}
\hline \multirow{3}{*}{$\begin{array}{l}T_{1} \text { plant } \\
\text { number }^{a}\end{array}$} & \multirow{3}{*}{$\begin{array}{l}\text { Cas9 } \\
\text { integration }\end{array}$} & \multicolumn{5}{|l|}{ Number of $T_{2}$ seeds } \\
\hline & & \multicolumn{3}{|l|}{ Mutation } & \multirow{2}{*}{$\begin{array}{l}\text { No } \\
\text { mutation }\end{array}$} & \multirow[t]{2}{*}{ Total } \\
\hline & & Gly $m$ Bd $28 \mathrm{~K}$ and $G l y m$ Bd $30 \mathrm{~K}$ & Gly $m$ Bd $28 K$ only & Gly $m$ Bd $30 K$ only & & \\
\hline \multirow[t]{2}{*}{ E1-1 } & positive & 16 & 10 & 3 & 0 & 29 \\
\hline & free & 2 & 1 & 5 & 2 & 10 \\
\hline \multirow[t]{2}{*}{ E1-2 } & positive & 21 & 0 & 0 & 0 & 21 \\
\hline & free & 1 & 0 & 3 & 0 & 4 \\
\hline \multirow[t]{2}{*}{ E1-5 } & positive & 8 & 4 & 0 & 1 & 13 \\
\hline & free & 1 & 0 & 3 & 0 & 4 \\
\hline \multirow[t]{2}{*}{ E2-1 } & positive & 0 & 20 & 0 & 5 & 25 \\
\hline & free & 0 & 2 & 0 & 5 & 7 \\
\hline \multirow[t]{2}{*}{ E2-2 } & positive & 1 & 20 & 0 & 0 & 21 \\
\hline & free & 0 & 0 & 0 & 5 & 5 \\
\hline \multirow[t]{2}{*}{ K1-1 } & positive & 9 & 1 & 0 & 0 & 10 \\
\hline & free & 3 & 0 & 0 & 0 & 3 \\
\hline \multirow[t]{2}{*}{$\mathrm{K} 1-3$} & positive & 13 & 3 & 0 & 0 & 16 \\
\hline & free & 3 & 0 & 4 & 2 & 9 \\
\hline \multirow[t]{2}{*}{ K2-1 } & positive & 16 & 3 & 1 & 0 & 20 \\
\hline & free & 1 & 0 & 2 & 0 & 3 \\
\hline \multirow[t]{2}{*}{ K2-2 } & positive & 19 & 7 & 0 & 0 & 26 \\
\hline & free & 1 & 0 & 4 & 0 & 5 \\
\hline \multirow[t]{2}{*}{ K4-1 } & positive & 33 & 0 & 2 & 0 & 35 \\
\hline & free & 2 & 0 & 0 & 0 & 2 \\
\hline \multirow[t]{2}{*}{ K5-1 } & positive & 50 & 0 & 0 & 0 & 50 \\
\hline & free & 0 & 0 & 0 & 0 & 0 \\
\hline \multirow[t]{2}{*}{ K5-2 } & positive & 14 & 1 & 0 & 0 & 15 \\
\hline & free & 0 & 0 & 0 & 0 & 0 \\
\hline \multirow[t]{2}{*}{ K6-1 } & positive & 12 & 3 & 0 & 0 & 15 \\
\hline & free & 0 & 0 & 0 & 0 & 0 \\
\hline
\end{tabular}

${ }^{\mathrm{a}}$ The letter and first number correspond to the number of the parental $\mathrm{T}_{0}$ plant

amplified products of the $18 \mathrm{~S}$ ribosomal RNA (18S rRNA) were detected at similar levels in all mature seeds of the mutants, Enrei, and Kariyutaka (Fig. 5), all mutants showed lower expression levels of the Gly $m B d$ $28 \mathrm{~K}$ and $\mathrm{Gly} \mathrm{m} \mathrm{Bd} 30 \mathrm{~K}$ genes than those of wild-type (Enrei and Kariyutaka) seeds (Fig. 5).

\section{Whole-genome sequencing in $\mathrm{T}_{2}$ plants to validate the absence of foreign DNA}

$\mathrm{T}_{2}$ mutant plants $\mathrm{K} 2-1-16$ and $\mathrm{K} 4-1-37$ were selected for whole-genome sequencing analysis. These plants had homozygous mutant alleles in both loci. The K2-1-16 plant had mutant alleles with a single-nucleotide insertion in the Gly $m B d 28 \mathrm{~K}$ and a 2-nucleotide deletion in the Gly $m$ Bd $30 \mathrm{~K}$ loci. The genome of K4-1-37 contained mutant alleles with a 6-nucleotide deletion in the Gly $m$ Bd $28 \mathrm{~K}$ locus and a 2-nucleotide deletion in the
Gly $m$ Bd $30 \mathrm{~K}$ locus. PCR analysis detected the presence of the Cas 9 gene in the genome of K2-1-16, whereas K4-1-37 was Cas9 free. The whole genomes of the two $\mathrm{T}_{2}$ plants were sequenced, and the presence of foreign DNA was examined by the $k$-mer detection method [42]. Each 20-mer identical between the plant genome and the vector was detected (Fig. 6). The genome of K2-116 clearly showed significant signals in a vector-wide manner (Fig. 6a, c), whereas that of K4-1-37 had no signal of foreign DNA from the vector (Fig. 6b). A significant signal found in the G-statistic of K4-1-37 was considered as a false positive, because it had a much lower value than that of $\mathrm{K} 2-1-16$.

\section{Morphological characteristics of double mutants}

To assess the consequences of the site-directed mutagenesis in the targeted loci, we examined the 


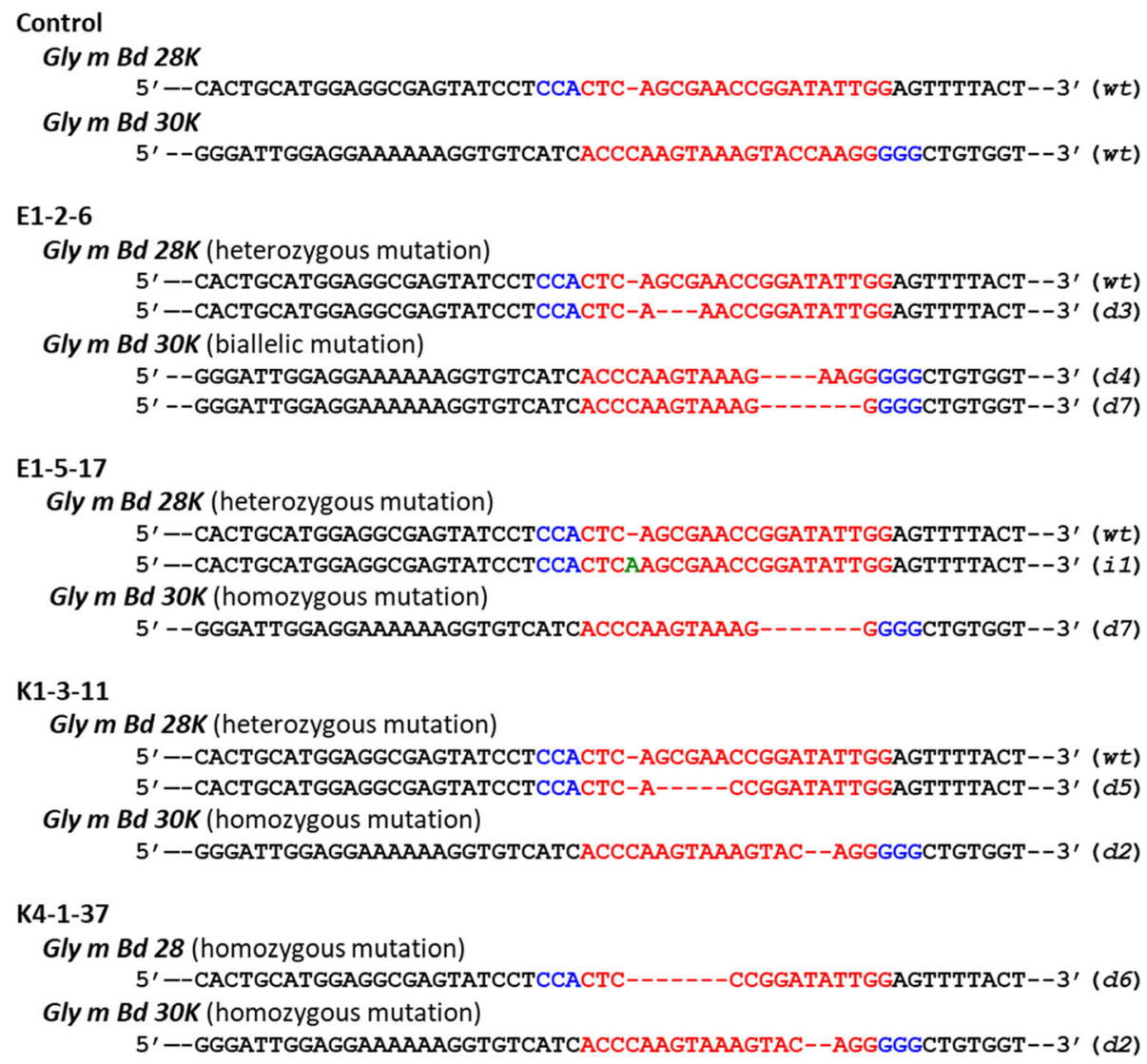

Fig. 3 Mutational spectra of the targeted loci in double-mutant $T_{2}$ seeds. Red and blue nucleotide sequences have the same meaning as those in Fig. 1. Green nucleotide denotes an insertion. Letters and numbers in parentheses indicate the type of mutation in the targeted locus: e.g., $d 1$, a single-nucleotide deletion; il, a single-nucleotide insertion; wt, no mutation. Control, reference sequence (Enrei or Kariyutaka)

morphology of the mutant plants. Because many mutant alleles in the targeted loci were detected in the Kariyutaka $\mathrm{T}_{2}$ generation (Fig. 3), we examined the morphological characteristics of $T_{2}$ plant body and $T_{3}$ seed size and shape. No difference was detected between the double-mutants and wild-type in the plant and seed morphological characteristics (Additional file 2: Figures S10, S11).

\section{Discussion}

Gly $\mathrm{m} \mathrm{Bd} 28 \mathrm{~K}$ and Gly $\mathrm{m} \mathrm{Bd} 30 \mathrm{~K}$ are the major allergenic proteins in soybean seeds $[6,43]$. The mutant alleles of these loci have been identified by surveying the soybean germplasm or generated by gamma-ray irradiation mutagenesis $[19,44,45]$, and stacking of these mutant alleles will enable development of hypoallergenic soybean lines. In contrast, site-directed mutagenesis mediated by the CRISPR/ Cas9 system enables the induction of mutations directly in the targeted loci of the desirable donor plants such as varieties and elite breeding lines. This approach dramatically shortens breeding period and saves labor. In this study, we performed simultaneous site-directed mutagenesis of both Gly $m B d 28 \mathrm{~K}$ and Gly $\mathrm{m} \mathrm{Bd} 30 \mathrm{~K}$ loci in two Japanese soybean varieties. A total of $14 \mathrm{~T}_{2}$-generation seeds possessed mutant alleles of both loci and had the Cas 9 gene removed through genetic segregation (Table 3). Among all mutations, deletions were predominant and caused frame-shifts (Additional file 2: Figures S4-S6). The frame-shift mutations resulted in the deficiency in proteins recognized by the polyclonal antibodies against Gly $\mathrm{m} \mathrm{Bd} 28 \mathrm{~K}$ and Gly m Bd $30 \mathrm{~K}$ proteins (Fig. 4). No bands of unexpected size were detected with either of these antibodies (Fig. 4). Frame-shift mutations in the targeted loci decreased the expression levels of the Gly $m B d 28 K$ and the Gly $m B d$ $30 \mathrm{~K}$ genes (Fig. 5). These findings suggest that the frame-shift mutations produce aberrant mRNAs from the targeted locus, which induced nonsense mRNA decay (NMD), like in a site-directed mutagenesis study conducted in Brassica carinata using the hairy root transformation system [46]. The lower expression level than wild-type might result in the 
Table 3 Mutational spectra in double-mutant $T_{3}$ plants

\begin{tabular}{|c|c|c|c|}
\hline Donor plant & Haplotype & Gly $m$ Bd $28 K$ locus & Gly $\mathrm{m} \mathrm{Bd} 30 \mathrm{~K}$ locus \\
\hline \multirow[t]{4}{*}{ Enrei } & E-type1 & $i 1, i 1$ & $d 7, d 7$ \\
\hline & E-type2 & $d 3, d 3$ & $d 33, d 33$ \\
\hline & E-type3 & $d 3, d 3$ & $d 7, d 7$ \\
\hline & E-type4 & $d 3, d 3$ & $d 4, d 4$ \\
\hline \multirow[t]{21}{*}{ Kariyutaka } & K-type1 & $i 1, i 1$ & $d 5, d 5$ \\
\hline & K-type2 & $d 5, d 5$ & $d 2, d 2$ \\
\hline & K-type3 & $d 5, w t^{a}$ & $d 2, d 2$ \\
\hline & K-type4 & $d 5, d 5$ & $d 1, d 1$ \\
\hline & K-type5 & $d 5, d 5$ & $d 6, d 6$ \\
\hline & K-type6 & $d 5, d 5$ & $d 1, d 6^{b}$ \\
\hline & K-type7 & $d 5, d 5$ & d1s1, d1s1 \\
\hline & K-type8 & $d 5, d 5$ & $d 1 s 1, w t^{a}$ \\
\hline & K-type9 & $d 2, d 2$ & $d 1 s 1, d 1 s 1$ \\
\hline & K-type10 & $d 2, d 2$ & $d 1 s 1, w t^{a}$ \\
\hline & K-type11 & $d 2, d 5^{b}$ & $d 1 s 1, d 1 s 1$ \\
\hline & K-type12 & $d 2, d 5^{b}$ & $d 1 s 1, w t^{a}$ \\
\hline & K-type13 & $d 2, d 5^{b}$ & $d 1, d 1$ \\
\hline & K-type14 & $i 1, i 1$ & $d 43, d 43$ \\
\hline & K-type15 & $i 1, i 1$ & $d 1, d 1$ \\
\hline & K-type16 & $i 1, i 1$ & $d 1, d 43^{b}$ \\
\hline & K-type17 & $i 1, w t^{\mathrm{a}}$ & $d 1, d 43^{b}$ \\
\hline & K-type18 & $d 6, d 6$ & $d 3, d 3$ \\
\hline & K-type19 & $i 1, i 1$ & $d 2, d 2$ \\
\hline & K-type20 & $i 1, i 1$ & $d 2, d 1^{b}$ \\
\hline & K-type21 & $d 6, d 6$ & $d 2, d 2$ \\
\hline
\end{tabular}

Letters and numbers denote the alleles in the targeted loci: e.g., d1, a singlenucleotide deletion; $i 1$, a single-nucleotide insertion; $d 1 s 1$, a single-nucleotide deletion and substitution; $w t$, wild type

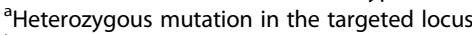

${ }^{\mathrm{b}}$ Biallelic mutations in the targeted locus

deficiency in proteins recognized by the polyclonal antibodies against Gly m Bd $28 \mathrm{~K}$ and Gly m Bd $30 \mathrm{~K}$ proteins. On the other hand, several $\mathrm{T}_{3}$ seeds had mutant alleles with putative in-frame mutations (Additional file 2: Figures S6, S7). The E-type3 haplotype with a 3-nucleotide deletion in the Gly $m$ Bd $28 \mathrm{~K}$ locus showed a strong immunoreactive band with the antibody against the Gly $\mathrm{m} \mathrm{Bd} 28 \mathrm{~K}$ protein, whereas the expression level of the Gly $m B d 28 \mathrm{~K}$ gene was lower than that in Enrei (Fig. 5). In this study, the expression level of the targeted loci was examined in only mature seeds of representative mutants and wild-type. Soybean seeds accumulate Gly m Bd $28 \mathrm{~K}$ and Gly $\mathrm{m}$ Bd $30 \mathrm{~K}$ proteins during seed filling [47]. Therefore, an investigation of the expression level of the targeted loci in immature seeds might lead to further understanding of accumulation mechanism of mutant proteins.
At least three immunodominant epitopes in Gly $\mathrm{m} \mathrm{Bd}$ $28 \mathrm{~K}$ and five in Gly $\mathrm{m} \mathrm{Bd} 30 \mathrm{~K}$ have been identified [48-50]. In this study, gRNAs were designed against the fourth exon of Gly $\mathrm{m} \mathrm{Bd} 28 \mathrm{~K}$ and first exon of Gly $\mathrm{m}$ $B d 30 \mathrm{~K}$ (Fig. 1). Immunodetection of proteins generated by the in-frame mutations in $\mathrm{T}_{3}$ seeds would indicate the presence proteins with preserved epitopes (Additional file 2: Figures S6, S7). Analysis of sera of soybeanallergic patients may further clarify the allergenic properties of soybean seeds generated in this study.

Multiple mutant alleles were detected in the progeny of one $\mathrm{T}_{0}$ plant (Fig. 7). Three mutant alleles (i1, $d 2$, and $d 5)$ in the Gly $m B d 28 \mathrm{~K}$ locus and five $(d 1, d 2, d 5$, $d 6$, and $d 1 s 1)$ mutant alleles in the Gly $m$ Bd $30 \mathrm{~K}$ locus were ascertained in the Cas9-free $\mathrm{T}_{2}$ and $\mathrm{T}_{3}$ seeds derived from the $\mathrm{K} 1 \mathrm{~T}_{0}$ plant (Fig. 7). These mutations appeared after the $T_{2}$ generation, when the distribution of mutant alleles in the targeted loci was validated in the genealogy of the K1 plant and its progeny (Fig. 7). Twelve haplotypes (K-type1 to K-type12) were consequently obtained in the Cas 9 -free $\mathrm{T}_{3}$ seeds (Fig. 7). Previously, we showed that simultaneous site-directed mutagenesis of duplicated loci using a single gRNA resulted in heterozygous and/or chimeric mutations in the targeted loci in most of the $\mathrm{T}_{1}$ plants [36]. On the other hand, the mutant alleles of multiple targeted loci have been induced in early generations such as $\mathrm{T}_{0}$ or $\mathrm{T}_{1}$ plants in other studies on soybean site-directed mutagenesis by the CRISPR/Cas9 system [37, 51, 52]. This difference might be explained by different growth and maturity habits of the soybean varieties used. Kariyutaka has early flowering and a short period of vegetative growth [53]; the latter might decrease the chance of the occurrence of mutations in germ cells in the $T_{0}$ generation, however, might produce multiple mutant alleles after the $\mathrm{T}_{1}$ generation. Therefore, the site-directed mutagenesis using Kariyutaka might be useful system for obtaining multiple mutant alleles in targeted genes efficiently in a limited number of transgenic soybean plants.

\section{Conclusion}

We used Agrobacterium-mediated transformation and two gRNAs for simultaneous site-directed mutagenesis of two allergenic genes, Gly $m$ Bd $28 \mathrm{~K}$ and Gly $m$ Bd $30 \mathrm{~K}$, in two Japanese soybean varieties. Cas 9 -free plants that had mutant alleles of the targeted loci and transgenes excluded by genetic segregation were obtained in the $T_{2}$ or $T_{3}$ generation. Immunoblot analysis revealed that the double-mutants did not accumulate Gly $\mathrm{m} \mathrm{Bd}$ $28 \mathrm{~K}$ or Gly $\mathrm{m} \mathrm{Bd} 30 \mathrm{~K}$ protein in mature seeds. Our results showed that simultaneous site-directed mutagenesis by the CRISPR/Cas9 system removed two major allergenic proteins in mature soybean seeds. 
A

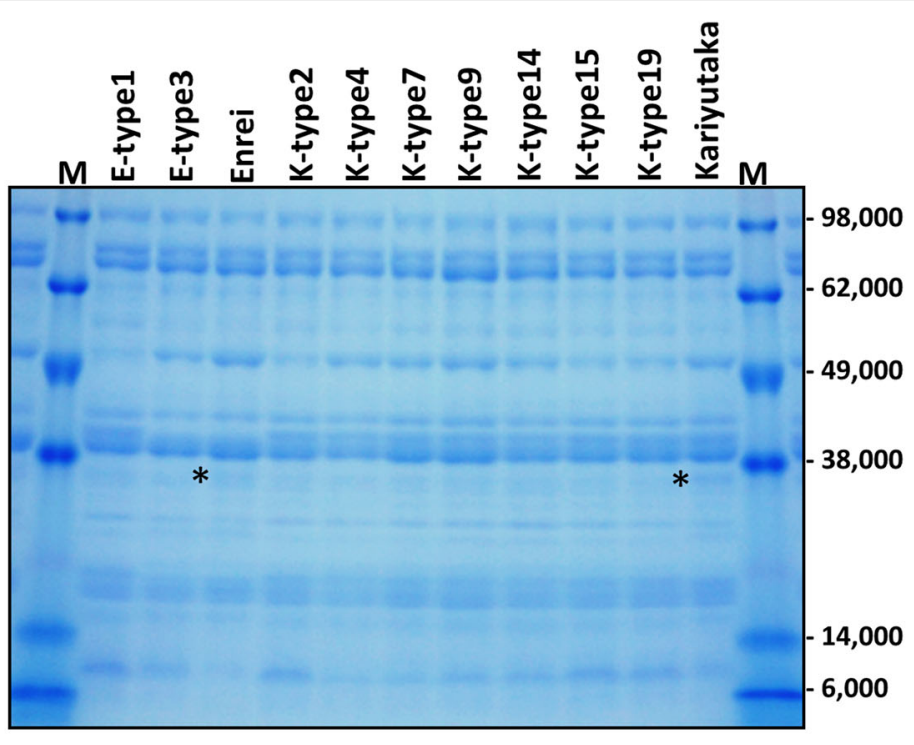

B

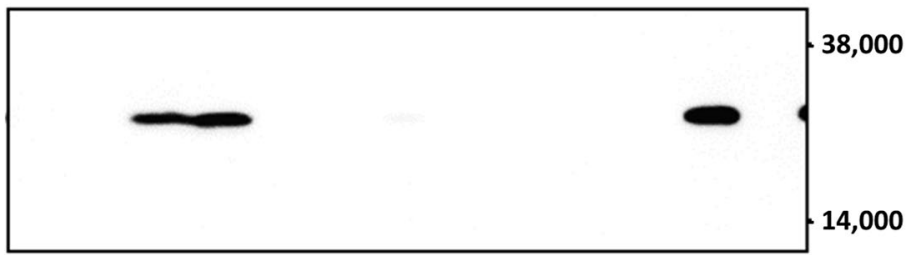

C

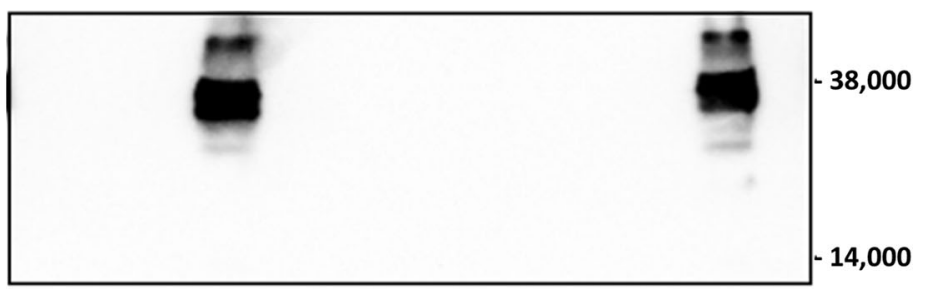

Fig. 4 SDS-PAGE and immunoblot analyses of the crude proteins of representative double-mutant $T_{3}$ and wild-type mature seeds. a Proteins separated by SDS-PAGE and stained with Coomasie Brilliant Blue. Designations of mutations are as in Table 3. Asterisks denote signal of putative Gly $\mathrm{m}$ Bd $30 \mathrm{~K}$ protein. M, molecular weight marker. b Immunoblot analysis using polyclonal antibody against Gly $\mathrm{m}$ Bd $28 \mathrm{~K}$ protein. c Immunoblot analysis using polyclonal antibody against Gly $\mathrm{m} \mathrm{Bd} 30 \mathrm{~K}$ protein. Gly $\mathrm{m} \mathrm{Bd} 30 \mathrm{~K}$ protein. Images of full-length gel and blots are provided in additional file 2 (Figure S8)

\section{Methods}

\section{Vector construction}

We constructed a gRNA expression vector (pLeg-base) which contained two gRNA expression cassettes. The frame sequence of the gRNA scaffold was derived from the vector pEn-Chimera [54]. Promoter regions of Arabidopsis U6-26 [54] and soybean U6-16g [55] were used to control gRNA and gRNA scaffold expression (Fig. 1b). The soybean allergenic genes Gly m Bd $28 \mathrm{~K}$ (Glyma.U020300.1) and Gly $m$ Bd 30 K (Glyma.08G116300.1) were the targets for simultaneous site-directed mutagenesis (Fig. 1a). Two 20-nucleotide sequences (5'-CTCAGCGA ACCGGATATTGG-3' and 5' 'ACCCAAGTAAAGTA
CCAAGG-3') identical in each gene were used to design the gRNA sequences with the web-based CRISPR-P 2.0 (http://crispr.hzau.edu.cn/CRISPR2/). The pLeg-base vector was digested with the BbsI or BsaI restriction enzyme (NEB, Ipswich, USA). Oligonucleotides designed to match the gene-specific sequence were annealed to each other to form the gRNA seed sequence, which was ligated into pLeg-base. The CRISPR/Cas9 expression plasmid (pMR284_28K_30K) was constructed by inserting the gRNA expression cassettes of pLeg-base into a Cas9-binary vector (pMR284) harboring Cas 9 and glufosinate resistance gene (Bar) expression cassettes using LR Clonase (Thermo Fisher Scientific, Waltham, USA). 


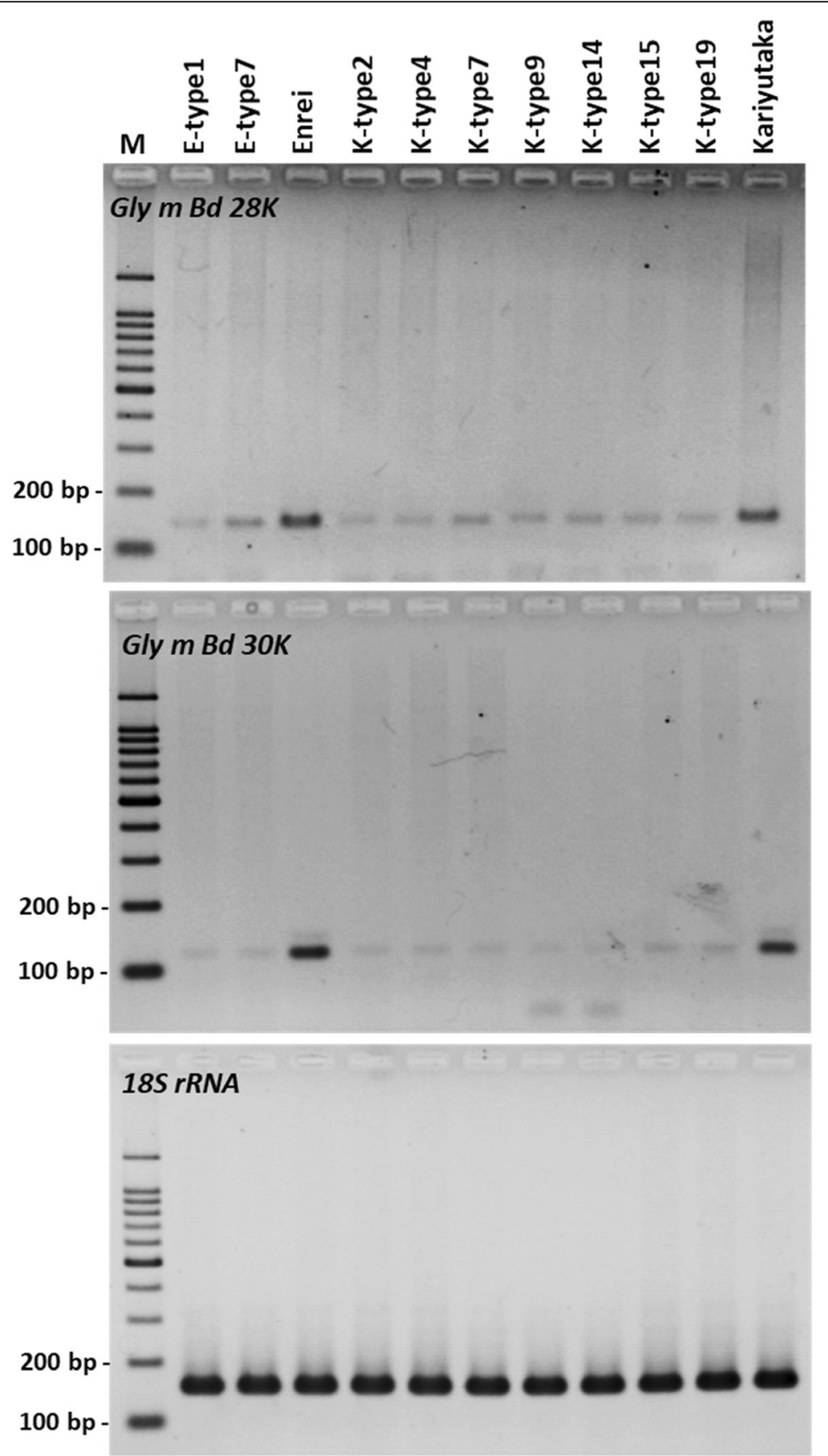

Fig. 5 Semi-quantitative RT-PCR of the Gly $m$ Bd $28 K$ and the Gly $m$ Bd $30 K$ genes mature seeds of representative double-mutant $T_{3}$ and wildtype mature seeds. The expression level of targeted loci was evaluated based on the quantity amplified for 185 rRNA as a control endogenous gene. PCR was performed at 38 cycles for the Gly $m$ Bd $28 \mathrm{~K}$ and at 30 cycles for the Gly $\mathrm{m} \mathrm{Bd} 30 \mathrm{~K}$ and 185 rRNA

\section{Soybean transformation}

The Japanese soybean varieties Enrei (JP 28862) and Kariyutaka (JP 86520) were obtained from Genebank, National Agriculture and Food Research Organization (https://www.gene.affrc.go.jp/index_en.php). Agrobacterium-mediated transformation was performed as described in [28], except that the concentration of glufosinate for selection of transformed cells was decreased from $6 \mathrm{mg} / \mathrm{L}$ to $4 \mathrm{mg} / \mathrm{L}$ for Enrei. Agrobacterium tumefaciens EHA105 harboring the plasmid pMR284_28K_30K was used. Transgenic plants were grown in commercial soil (Katakura Chikkarin Co., 
A
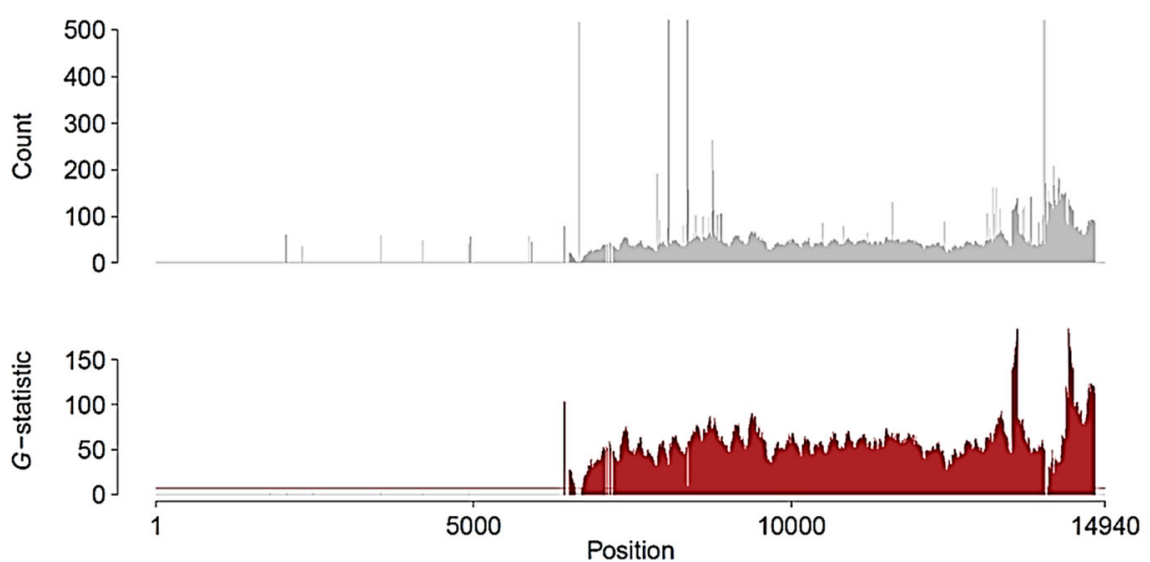

B
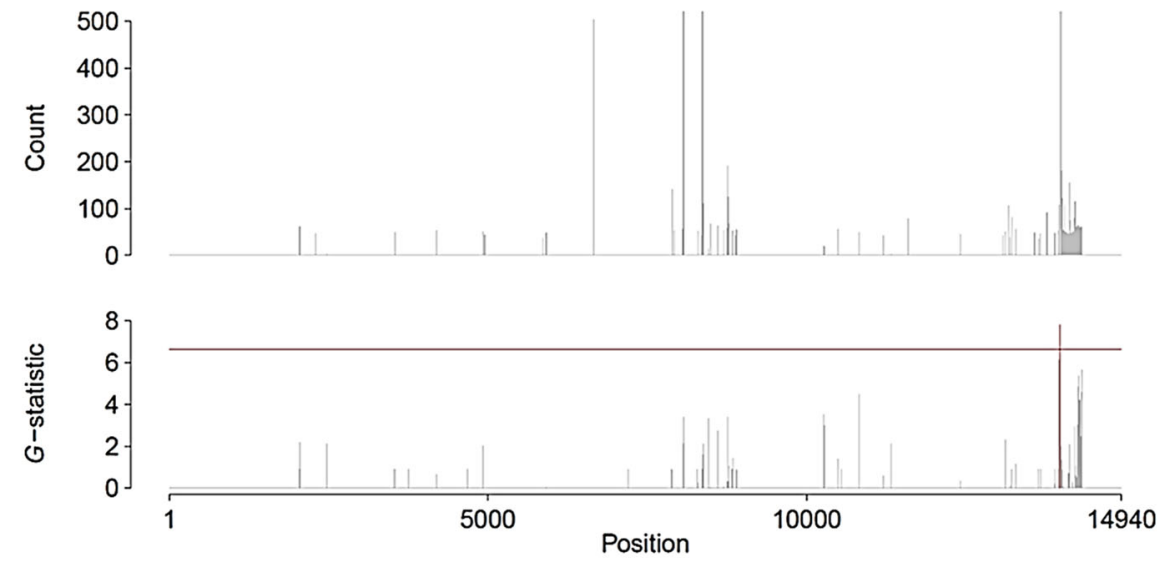

C

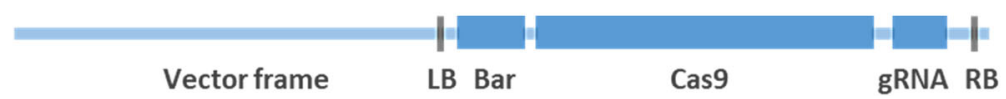

Fig. 6 Detection of unintended remaining foreign DNA in $T_{2}$ plants. The counts of $k$-mer and $G$-statistic are shown for (a) a transgenic sample K2-1-16 and (b) a Cas9-free sample K4-1-37. c Structure of the binary expression vector pMR284_28K_30K. The horizontal axis indicates the nucleotide positions in the vector; horizontal red line is the $1 \%$ significance level by $G$-test. G-statistic values exceeding the $1 \%$ level of significance are in red. The $k$-mer counts over 500 are omitted

Tokyo, Japan) at $25^{\circ} \mathrm{C}$ in an isolated greenhouse for transgenic plants.

\section{Extraction of genomic DNA and detection of mutations in} targeted loci by CAPS analysis

To extract leaf genomic DNA, leaf pieces (approximately $5 \mathrm{~mm} \times 5 \mathrm{~mm}$ ) were homogenized in $200 \mu \mathrm{L}$ of extraction buffer [ $2 \%$ CTAB (hexadecyltrimethyl-ammonium bromide), $100 \mathrm{mM}$ Tris- $\mathrm{HCl}$ (pH 8.0), $20 \mathrm{mM}$ EDTA (pH 8.0), $1.4 \mathrm{M} \mathrm{NaCl}$, and $0.07 \% \quad 2$ mercaptethanol] in a BioMasher II tube (Nippi, Tokyo, Japan). To extract genomic DNA from mature seeds, a part of cotyledon was powdered and approximately 5 $\mathrm{mg}$ of powder was stirred in extraction buffer $[10 \mathrm{mM}$
Tris- $\mathrm{HCl}$ (pH 8.0), 5 mM EDTA, 0.5\% SDS, 0.5\% NP40, $0.5 \%$ Tween 20 , and $80 \mathrm{mg} / \mathrm{L}$ proteinase- $\mathrm{K}$ (Wako, Osaka, Japan)]. The mixture was incubated at $50{ }^{\circ} \mathrm{C}$ for $1 \mathrm{~h}$. DNA extracts were deproteinized with a mixture of phenol, chloroform, and isoamyl alcohol (25:24:1). DNA was precipitated from the supernatant with 2propanol. The targeted regions in the Gly $m B d 28 \mathrm{~K}$ and Gly $m$ Bd $30 \mathrm{~K}$ loci were amplified by PCR with specific primers (Additional file 1: Table S3). The PCR was performed under the following conditions: $30 \mathrm{cy}-$ cles of $94{ }^{\circ} \mathrm{C}$ for $30 \mathrm{~s}, 54{ }^{\circ} \mathrm{C}$ (the Gly $m$ Bd $28 \mathrm{~K}$ ) or $60{ }^{\circ} \mathrm{C}$ (the Gly $\mathrm{m} \mathrm{Bd} 30 \mathrm{~K}$ ) for $30 \mathrm{~s}$ and $72{ }^{\circ} \mathrm{C}$ for $60 \mathrm{~s}$. The amplified products were digested with the DdeI and BsaJI restriction enzymes (NEB), respectively, and 


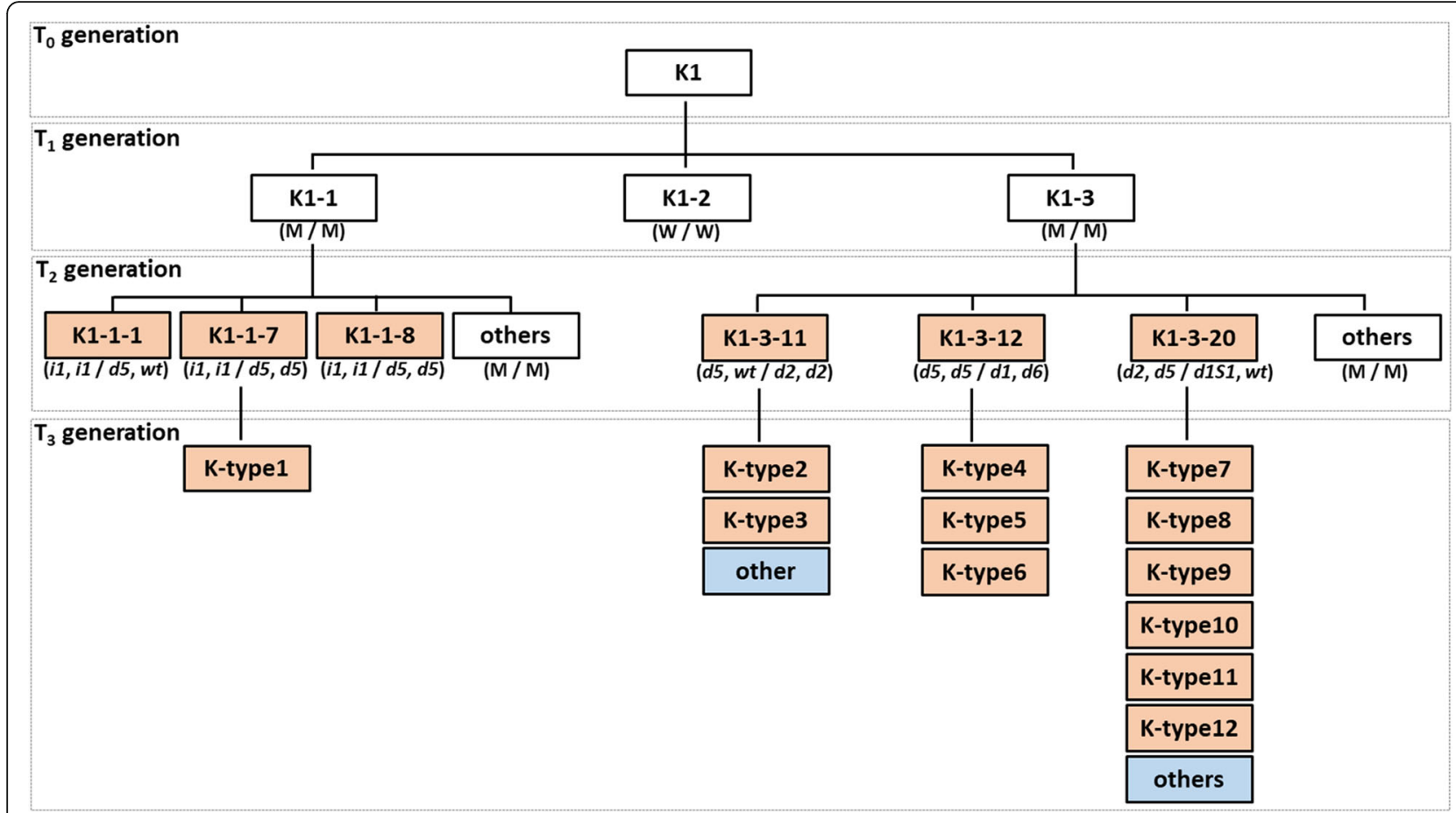

Fig. 7 Multiple mutant alleles in the targeted loci in descendants of one $T_{0}$ plant (K1). White boxes, transgenic; light orange boxes, Cas9-free double-mutants; light blue boxes, Cas9-free single mutants in the targeted loci. In parentheses ( $T_{0}$ and $\left.T_{1}\right)$ : $M$, mutant type; $W$, wild type. Designations of mutations $\left(T_{3}\right)$ are as in Table 3. In parentheses, the left description of "I" refers to genotypes of Gly $m$ Bd $28 \mathrm{~K}$ locus and the right one to genotypes to Gly $m$ Bd $30 \mathrm{~K}$ locus in all transgenic generations

separated by electrophoresis in $2.0 \%$ agarose gels. The DNA fragments of expected digested-pattern derived from the targeted region carrying mutations and those with no mutations were considered as the mutant type and wild type, respectively. DNA fragments of unexpected size were also regarded as mutant type.

\section{DNA sequencing}

The targeted and flanking regions of the Gly $m B d 28 \mathrm{~K}$ and Gly $m$ Bd $30 \mathrm{~K}$ loci were amplified with specific primers (Additional file 1: Table S3). The amplified products were cloned into the pGEM-T-Easy vector (Promega, Madison, USA) and sequenced with the Big Dye terminator cycle method using an ABI3100 or ABI3130 Genetic Analyzer (Thermo Fisher Scientific). DNA sequencing analysis was performed by the Instrumental Analysis Division, Graduate School of Agriculture, Hokkaido University.

\section{Selection of Cas9-free plants}

To confirm the integration of the Cas9 and gRNA expression module in $\mathrm{T}_{1}-\mathrm{T}_{3}$ generations, $\mathrm{PCR}$ analysis was performed using primers specific for the Cas 9 gene (Additional file 1: Table S3). PCR was also performed to simultaneously amplify endogenous Glyma.01G214600 as a positive control. The PCR was performed under the following conditions: 30 cycles of $94{ }^{\circ} \mathrm{C}$ for $30 \mathrm{~s}, 54^{\circ} \mathrm{C}$ for $30 \mathrm{~s}$ and $72{ }^{\circ} \mathrm{C}$ for $30 \mathrm{~s}$. The existence of the Cas 9 gene were identified by the existence of products amplified by the PCR.

\section{Protein analyses in mature seeds}

Soy meal was collected from mature seeds. The extraction of crude protein and protein separation were performed as described in [28]. Proteins were separated by SDS-PAGE in a precast $5-12 \%$ gradient gel (ATTO, Tokyo, Japan) and transferred onto a PVDF membrane (Hybond-P; GE Healthcare, Little Chalfont, UK). Membranes were blocked with $5 \%$ skim milk (Wako) overnight at $4{ }^{\circ} \mathrm{C}$. Recombinant Gly m Bd $30 \mathrm{k}$ was prepared using the baculovirus expression system as described in [5]. Using the pET52 vector (Merck-Millipore, Burlington, USA), His 10 -tagged Gly $\mathrm{m} \mathrm{Bd} 28 \mathrm{~K}$ was expressed in Escherichia coli BL21(DE3). After sonication and centrifugation, Gly $\mathrm{m}$ Bd $28 \mathrm{~K}$-containing pellets were dissolved in phosphate-buffered saline containing $8 \mathrm{M}$ urea, and Gly $\mathrm{m} \mathrm{Bd} 28 \mathrm{~K}$ was purified using a HisTrapFF crude column (GE Healthcare). Antisera were raised in rabbits against the recombinant proteins as described in [56]. Immunoreactive bands were detected with the antisera and the ECL Plus Western Blotting system (GE Healthcare). 


\section{Expression analysis by semi-quantitative RT-PCR}

Total RNA was extracted from mature seeds of mutants, Enrei, and Kariyutaka by the $\mathrm{LiCl}$ precipitation procedure [28]. Semi-quantitative RT-PCR was conducted in a $20-\mu \mathrm{L}$ volume using 30 or 38 cycles of $94{ }^{\circ} \mathrm{C}$ for $30 \mathrm{~s}, 57^{\circ} \mathrm{C}$ for $30 \mathrm{~s}$, and $72{ }^{\circ} \mathrm{C}$ for $10 \mathrm{~s}$. The transcript level of the Gly $\mathrm{m}$ $B d 28 \mathrm{~K}$ and the Gly $\mathrm{m} \mathrm{Bd} 30 \mathrm{~K}$ gene was evaluated relative to that of the 18S rRNA gene (XR_003264275).

\section{Genome sequencing}

Total DNA was isolated from fresh leaves $(1.0-2.0 \mathrm{~g})$ of wild-type and $\mathrm{T}_{2}$ plants as described in [41]. Genomic DNA libraries were constructed using a TruSeq DNA PCR-Free Library Preparation Kit (Illumina, San Diego, USA).Whole-genome sequencing was conducted on an Illumina HiSeq X platform to obtain 151-nt paired-end reads. Approximately $50 \times$ coverage data were obtained for each sample. Unintended remaining foreign DNA was detected as described in [42].

\section{Supplementary Information}

The online version contains supplementary material available at https://doi. org/10.1186/s12870-020-02708-6.

Additional file 1: Table S1. Induction of mutations in the targeted loci and the integration of the Cas 9 gene in representative $T_{1}$ plants from the transformation of Enrei. Table S2. Induction of mutations in the targeted loci and the integration of the Cas 9 gene in representative $T_{1}$ plants from the transformation of Kariyutaka. Table S3. Primer sequences used for vector construction, confirmation of transgenes, and CAPS, semiquantitative RT-PCR, and sequencing analyses.

Additional file 2: Figure S1. Confirmation of mutagenesis of targeted loci in representative Kariuytaka- $T_{1}$ plants by CAPS analysis. Figure S2. Detection of mutations in the Gly $m$ Bd 28K and Gly $m$ Bd 30K loci in representative Enrei- $T_{2}$ seeds by CAPS analysis. Figure S3. Detection of mutations in the Gly $m$ Bd $28 \mathrm{~K}$ and Gly $m$ Bd 30K loci in representative Kariyutka- $T_{2}$ seeds by CAPS analysis. Figure S4. Detection of the integration of the Cas9 gene in representative $T_{2}$ seeds by PCR analysis. Figure S5. Mutational spectra of the targeted loci in double-mutant $T_{3}$ seeds. Figure S6. Alignment of predicted amino acid sequences of the Gly $\mathrm{m}$ Bd $28 \mathrm{~K}$ locus in double mutants. Figure S7. Alignment of predicted amino acid sequences of the Gly $m$ Bd $30 K$ locus in double mutants. Figure S8. Full-length gel electrophoresis and immunoblot of the crude protein of representative double-mutant $T_{3}$ and wild-type mature seeds. Figure S9. Primer sites used for semi-quantitative RT-PCR analysis of the Gly $m$ Bd $30 K$ and the Gly $m$ Bd 30K loci. Figure S10. Morphological characteristics of representative double-mutant $\left(\mathrm{T}_{2}\right)$ and control Kariyutaka plants. Figure S11. Morphological characteristics of representative double-mutant $\left(T_{3}\right)$ and control Kariyutaka seeds.

\section{Abbreviations}

PVDF: Polyvinylidene difluoride; SDS-PAGE: Sodium dodecyl sulfatepolyacrylamide gel electrophoresis

\section{Acknowledgements}

We thank Professor Holger Puchta (University of Karlsruhe) for permission to use plasmid DNA of pEn-Chimera, Dr. Mily Ron and Professor Anne Britt (UC Davis) for kindly supply of pMR284, and M. Suzuki, S. Noguchi, Y. Kitsui, and R. Onuki for general technical assistance. We thank the DASH (Development and Assessment of Sustainable Humanosphere) system for supporting the experiment.

\section{Authors' contributions}

SS, JA, and TY: conceived and designed the experiments; $A H, Y K, M M, M E$, and $\mathrm{SH}$ : constructed vectors; SS, AH, and YK: performed site-directed mutagenesis; SS, KA, MH, and NM: analyzed mutations in transgenic soybean; TI: analyzed unintended remaining foreign DNA; SS, JA, and TY: contributed to the writing the manuscript. All authors have read and approved the manuscript.

\section{Funding}

This work was supported by the Cabinet Office, Government of Japan [the Cross-ministerial Strategic Innovation Promotion Program (SIP)] to TY. The funding agency was not involved in the designing of the study and collection, analysis and interpretation of the data, and in the writing of the manuscript.

\section{Availability of data and materials}

The datasets supporting this study are included within the manuscript and its additional files. The vector developed in this study is available from the corresponding author on reasonable request. The datasets of genomic sequence in Kariyutaka and mutants (K2-1-16 and K4-1-37) have been deposited in the DDBJ Sequence Read Archive under the BioProject Accession PRJDB10633.

Ethics approval and consent to participate

Not applicable.

\section{Consent for publication}

Not applicable.

\section{Competing interests}

The authors declare that they have no competing interests.

\section{Author details}

${ }^{1}$ Graduate School of Agriculture, Hokkaido University, Kita 9, Nishi 9, Kita-ku, Sapporo, Hokkaido 060-8589, Japan. Bioinformatics Team, Advanced Analysis Center, National Agricultural and Food Research Organization, 2-1-2 Kannondai, Tsukuba, Ibaraki 305-8602, Japan. ${ }^{3}$ Plant Genome Engineering Research Unit, Institute of Agrobiological Sciences, National Agricultural and Food Research Organization, 1-2, Owashi, Tsukuba, Ibaraki 305-8634, Japan. ${ }^{4}$ Graduate School of Agriculture, Kyoto University, Uji, Kyoto 611-0011, Japan.

Received: 26 June 2020 Accepted: 19 October 2020 Published online: 11 November 2020

\section{References}

1. Liu K. Soybean as functional foods and ingredients. New York: Chapman \& Hall; 1997.

2. Utsumi S, Damodaran S, Kinsella JE. Heat-induced interactions between soybean proteins - preferential association of $11 \mathrm{~S}$ basic subunits and betasubunits of 7S. J Agric Food Chem. 1984;32:1406-12.

3. Nagano T, Mori H, Nishinari K. Effect of heating and cooling on the gelation kinetics of 75 globulin from soybeans. J Agric Food Chem. 1994;42:1415-9.

4. Heppell LM, Sissons JW, Pedersen HE. A comparison of the antigenicity of soya-bean-based infant formulas. Br J Nutr. 1987;58:393-403.

5. Maruyama N, Sato S, Cabanos C, Tanaka A, Ito K, Ebisawa M. Gly m 5/Gly m 8 fusion component as a potential novel candidate molecular for diagnosing soya bean allergy in Japanese children. Clin Exp Allergy. 2018;48: 1726-34.

6. Ogawa T, Tsuji H, Bando N, Kitamura K, Zhu YL, Hirano H, et al. Identification of the soybean allergenic protein, Gly-m Bd 30k, with the soybean seed 34kDa oil-body-associated protein. Biosci Biotechnol Biochem. 1993;57:1030-3.

7. Tsuji H, Bando N, Hiemori M, Yamanishi R, Kimoto M, Nishikawa K, et al. Purification and characterization of soybean allergen Gly m Bd 28K. Biosci Biotechnol Biochem. 1997:61:942-7.

8. Gonzalez R, Polo F, Zapatero L, Caravaca F, Carreira J. Purification and characterization of major inhalant allergens from soybean hulls. Clin Exp Allergy. 1992;22:748-55.

9. Codina R, Lockey RF, Fernandez-Caldas E, Rama R. Purification and characterization of a soybean hull allergen responsible for the Barcelona asthma outbreaks. 2. Purification and sequencing of the Gly $\mathrm{m} 2$ allergen. Clin Exp Allergy. 1997;27:424-30. 
10. Rihs HP, Chen ZP, Rueff F, Petersen A, Rozynek P, Heimann H, et al. IgE binding of the recombinant allergen soybean profilin (rGly $\mathrm{m} 3$ ) is mediated by conformational epitopes. J Allergy Clinic Immun. 1999;104: 1293-301.

11. Kleine-Tebbe J, Wangorsch A, Vogel L, Crowell DN, Haustein UF, Vieths S. Severe oral allergy syndrome and anaphylactic reactions caused by a bet $v$ 1-related PR-10 protein in soybean, SAM22. J Allergy Clinic Immun. 2002; 110:797-804.

12. Ogawa T, Samoto M, Takahashi K. Soybean allergens and hypoallergenic soybean products. J Nutr Sci Vitaminol. 2000;46:271-9.

13. Thanh VH, Shibasaki K. Major proteins of soybean seeds - straightforward fractionation and their characterization. J Agric Food Chem. 1976;24:111721.

14. Iwabuchi S, Yamauchi F. Electrophoretic analysis of whey proteins present in soybean globulin fractions. J Agric Food Chem. 1987;35:205-9.

15. Samoto M, Maebuchi M, Miyazaki C, Kugitani H, Kohno M, Hirotsuka M, et al. Abundant proteins associated with lecithin in soy protein isolate. Food Chem. 2007;102:317-22.

16. Samoto M, Akasaka T, Mori H, Manabe M, Ookura T, Kawamura Y. Simple and efficient procedure for removing the $34 \mathrm{kDa}$ allergenic soybean protein, Gly $m$ I, from defatted soy milk. Biosci Biotechnol Biochem. 1994;58:2123-5.

17. Mori T, Utsumi S, Inaba H, Kitamura K, Harada K. Differences in composition of glycinin among soybean cultivars. J Agric Food Chem. 1981;29:20-3.

18. Kitamura K, Davies CS, Nielsen NC. Inheritance of alleles for $\mathrm{Cgy}_{1}$ and $\mathrm{Gy}_{4}$ storage protein genes in soybean. Theor Appl Genet. 1984;68:253-7.

19. Takahashi K, Banba H, Kikuchi A, Ito M, Nakamura S. An induced mutant line lacking the a-subunit of $\beta$-conglycinin in soybean [Glycine max (L.) Merrill]. Breed Sci. 1994:44:65-6.

20. Hajika M, Takahashi M, Sakai SJ, Igita K. A new genotype of $7 \mathrm{~S}$ globulin (beta-conglycinin) detected in wild soybean (Glycine soja Sieb et Zucc). Breed Sci. 1996:46:385-6

21. Tsubokura Y, Hajika M, Kanamori H, Xia ZJ, Watanabe S, Kaga A, et al. The $\beta$ conglycinin deficiency in wild soybean is associated with the tail-to-tail inverted repeat of the a-subunit genes. Plant Mol Biol. 2012;78(3):301-9.

22. Hajika M, Takahashi M, Sakai S, Matsunaga R. Dominant inheritance of a trait lacking $\beta$-conglycinin detected in a wild soybean line. Breed Sci. 1998;48: 383-6.

23. Takahashi K, Mizuno Y, Yumoto S, Kitamura K, Nakamura S. Inheritance of the a-subunit deficiency of $\beta$-conglycinin in soybean (Glycine max L MERR ILL) line induced by gamma-ray irradiation. Breed Sci. 1996;46:251-5.

24. Manjaya JG, Suseelan KN, Gopalakrishna T, Pawar SE, Bapat VA. Radiation induced variability of seed storage proteins in soybean Glycine max (L.) Merrill. Food Chem. 2007;100:1324-7.

25. Schmidt MA, Hymowitz T, Herman EM. Breeding and characterization of soybean triple null; a stack of recessive alleles of Kunitz trypsin inhibitor, soybean agglutinin, and P34 allergen nulls. Plant Breed. 2015;134:310-5.

26. Herman EM, Helm RM, Jung R, Kinney AJ. Genetic modification removes an immunodominant allergen from soybean. Plant Physiol. 2003;132:36-43.

27. Nishizawa K, Takagi K, Teraishi M, Kita A, Ishimoto M. Application of somatic embryos to rapid and reliable analysis of soybean seed components by RNA interference-mediated gene silencing. Plant Biotechnol. 2010;27:409-20.

28. Yamada T, Mori Y, Yasue K, Maruyama N, Kitamura K, Abe J. Knockdown of the 75 globulin subunits shifts distribution of nitrogen sources to the residual protein fraction in transgenic soybean seeds. Plant Cell Rep. 2014; 33:1963-76.

29. Cermak T, Doyle EL, Christian M, Wang L, Zhang Y, Schmidt C, et al. Efficient design and assembly of custom TALEN and other TAL effector-based constructs for DNA targeting. Nucleic Acids Res. 2011;39:82.

30. Li JF, Norville JE, Aach J, McCormack M, Zhang DD, Bush J, et al. Multiplex and homologous recombination-mediated genome editing in Arabidopsis and Nicotiana benthamiana using guide RNA and Cas9. Nat Biotechnol. 2013;31:688-91.

31. Nekrasov V, Staskawicz B, Weigel D, Jones JDG, Kamoun S. Targeted mutagenesis in the model plant Nicotiana benthamiana using Cas9 RNAguided endonuclease. Nat Biotechnol. 2013;31:691-3.

32. Shan QW, Wang YP, Li J, Zhang Y, Chen KL, Liang Z, et al. Targeted genome modification of crop plants using a CRISPR-Cas system. Nat Biotechnol. 2013;31:686-8

33. Li ZS, Liu ZB, Xing AQ, Moon BP, Koellhoffer JP, Huang LX, et al. Cas9-guide RNA directed genome editing in soybean. Plant Physiol. 2015;169:960-70.
34. Cai Y, Chen L, Liu X, Guo C, Sun S, Wu C, et al. CRISPR/Cas9-mediated targeted mutagenesis of GmFT2a delays flowering time in soybean. Plant Biotechnol J. 2018;16:176-85

35. Curtin SJ, Xiong Y, Michno J-M, Campbell BW, Stec AO, Čermák T, et al. CRIS PR/Cas9 and TALENs generate heritable mutations for genes involved in small RNA processing of Glycine max and Medicago truncatula. Plant Biotechnol J. 2018;16:1125-37.

36. Kanazashi Y, Hirose A, Takahashi I, Mikami M, Endo M, Hirose S, et al. Simultaneous site-directed mutagenesis of duplicated loci in soybean using a single guide RNA. Plant Cell Rep. 2018;37:553-63.

37. Do PT, Nguyen CX, Bui HT, Tran LTN, Stacey G, Gillman JD, et al. Demonstration of highly efficient dual gRNA CRISPR/Cas9 editing of the homeologous GmFAD2-1A and GMFAD2-1B genes to yield a high oleic, low linoleic and a-linolenic acid phenotype in soybean. BMC Plant Biol. 2019;19:311.

38. Nakamura T, Utsumi S, Kitamura K, Harada K, Mori T. Cultivar differences in gelling characteristics of soybean glycinin. J Agric Food Chem. 1984; 32:647-51.

39. Tezuka $M$, Taira $H$, Igarashi $Y$, Yagasaki $K$, Ono $T$. Properties of tofus and soy milk prepared from soybeans having different subunits of glycinin. J Agric Food Chem. 2000:48:1111-7.

40. Maruyama N, Park K, Motoyama S, Choi S-K, Yagasaki K, Ishimoto M, et al. Structure-physicochemical function relationships of soybean glycinin at subunit levels assessed by using mutant lines. J Agric Food Chem. 2004;52: 8197-201.

41. Yamada T, Watanabe S, Arai M, Harada K, Kitamura K. Cotyledonary node pre-wounding with a micro-brush increased frequency of agrobacteriummediated transformation in soybean. Plant Biotechnol. 2010;27:217-20.

42. Itoh T, Onuki R, Tsuda M, Oshima M, Endo M, Sakai H, et al. Foreign DNA detection by high-throughput sequencing to regulate genome-editing agricultural products. Sci Rep. 2020;10:4914.

43. Ogawa T, Bando N, Tsuji H, Okajima H, Nishikawa K, Sasaoka K. Investigation of the lgE-binding proteins in soybeans by immunoblotting with the sera of the soybean-sensitive patients with atopic-dermatitis. J Nutr Sci Vitaminol. 1991;37:555-65.

44. Samoto M, Fukuda Y, Takahashi K, Tabuchi K, Hiemori M, Tsuji H, et al. Substantially complete removal of three major allergenic soybean proteins (Gly m Bd 30K, Gly m Bd 28K, and the a-subunit of conglycinin) from soy protein by using a mutant soybean, Tohoku 124. Biosci Biotechnol Biochem 1997:61:2148-50.

45. Joseph LM, Hymowitz T, Schmidt MA, Herman EM. Evaluation of Glycine germplasm for nulls of the immunodominant allergen P34/Gly m Bd 30k. Crop Sci. 2006:46:1755-63.

46. Kirchner TW, Niehaus M, Debener T, Schenk MK, Herde M. Efficient generation of mutations mediated by CRISPR/Cas9 in the hairy root transformation system of Brassica carinata. PLoS One. 2017;12:e185429.

47. Wu YM, Guan RX, Liu ZX, Li RZ, Chang RZ, Qiu LJ. Synthesis and degradation of the major allergens in developing and germinating soybean seed. J Integr Plant Biol. 2012;54:4-14.

48. Helm RM, Cockrell G, Herman E, Burks AW, Sampson HA, Bannon GA. Cellular and molecular characterization of a major soybean allergen. Int Arch Allergy Immunol. 1998;117:29-37.

49. Helm RM, Cockrell G, Connaughton C, West CM, Herman E, Sampson HA, et al. Mutational analysis of the lgE-binding epitopes of P34/Gly m Bd 30K. J Allergy Clin Immunol. 2000;105:378-84.

50. Xi J, Yan HL. Epitope mapping and identification of amino acids critical for mouse lgG-binding to linear epitopes on Gly m Bd 28K. Biosci Biotechnol Biochem. 2016:80:1973-9.

51. Cai YP, Wang LW, Chen L, Wu T, Liu LP, Sun S, et al. Mutagenesis of GmFT2 $a$ and GmFT5a mediated by CRISPR/Cas9 contributes for expanding the regional adaptability of soybean. Plant Biotechnol J. 2020;18:298-309.

52. Bao AL, Chen HF, Chen LM, Chen SL, Hao QN, Guo W, et al. CRISPR/Cas9mediated targeted mutagenesis of GMSPL9 genes alters plant architecture in soybean. BMC Plant Biol. 2019;19:131

53. Tsubokura $Y$, Watanabe $S$, Xia Z, Kanamori $H$, Yamagata $H$, Kaga A, et al. Natural variation in the genes responsible for maturity loci E1,E2,E3 and E4 in soybean. Ann Bot. 2014;113:429-41.

54. Fauser F, Schiml S, Puchta H. Both CRISPR/Cas-based nucleases and nickases can be used efficiently for genome engineering in Arabidopsis thaliana. Plant J. 2014;79:348-59. 
55. Du HY, Zeng XR, Zhao M, Cui XP, Wang $Q$, Yang $H$, et al. Efficient targeted mutagenesis in soybean by TALENs and CRISPR/Cas9. J Biotechnol. 2016; 217:90-7.

56. Nishizawa K, Maruyama N, Satoh R, Fuchikami Y, Higasa T, Utsumi SA. Cterminal sequence of soybean $\beta$-conglycinin a' subunit acts as a vacuolar sorting determinant in seed cells. Plant J. 2003;34:647-59.

\section{Publisher's Note}

Springer Nature remains neutral with regard to jurisdictional claims in published maps and institutional affiliations.

Ready to submit your research? Choose BMC and benefit from:

- fast, convenient online submission

- thorough peer review by experienced researchers in your field

- rapid publication on acceptance

- support for research data, including large and complex data types

- gold Open Access which fosters wider collaboration and increased citations

- maximum visibility for your research: over $100 \mathrm{M}$ website views per year

At BMC, research is always in progress.

Learn more biomedcentral.com/submissions 